\title{
Towards immunity of oil palm against Ganoderma fungus infection
}

\begin{abstract}
The first record of Ganoderma can be traced back to the Pharmacopoeia written by Chinese scientists in first century B.C. Several Ganoderma species are known as "white rot" fungi, which cause the display of the white cellulose on wood by degrading the lignin component. Ganoderma boninense is the main agent of basal stem rot (BSR) disease, as a persistent problem in the oil palm (Elaeis guineensis, Jacq.) cultivation that needs to be controlled. Oil palm, which is the main host of this pathogen, is an economically important crop grown in Southeast Asia, Africa, and America. Due to the negative effects of Ganoderma on the plants, especially on oil palm, this review focuses on the mechanisms of Ganoderma infection and its control, the importance of lignin and silicon (Si) to plant defense. This review also explores different methods for Ganoderma control and techniques for producing less susceptible oil palm. Genetic manipulation of oil palm for enhancing resistance to Ganoderma is also discussed.
\end{abstract}

Keyword: Innate immunity; Elaeis guineensis; Ganoderma boninense; Silicon; Serine-rich protein 